\title{
LOS ROMANCES "AÑADIDOS" DEL CANCIONERO DE ROMANCES: UNA HIPÓTESIS SOBRE EL FRAGMENTISMO DEL ROMANCERO VIEJO
}

\author{
THE “ADDED” ROMANCES IN THE \\ CANCIONERO DE ROMANCES: \\ A HYPOTHESIS ON THE FRAGMENTED \\ NATURE OF THE ROMANCERO VIEJO
}

\author{
Alejandro Higashi \\ Universidad Autónoma Metropolitana-Unidad Iztapalapa \\ higa@xanum.uam.mx
}

Resumen: Analizo los patrones de reescritura entre las versiones de varios romances publicadas en la primera edición del Cancionero de romances de Martín Nucio y la segunda, de 1550, bajo el concepto de versiones editoriales (aquellas que se construyen dentro de las mismas imprentas con el propósito de ofrecer textos mejorados). Aunque es muy probable que algunas de estas versiones procedan de un sustrato oral cortesano, en su gran mayoría se trata de arreglos textuales para proponer versiones más extensas y detalladas, fenómeno que obliga a repensar la naturaleza fragmentaria atribuida al romancero viejo.

Palabras clave: romancero; impresos del siglo xvi; Martín Nucio;

versión; reescritura.

Abstract: I analyze the patterns of rewriting evident in the different versions of several romances published in the first edition of Martín Nucio's Cancionero de romances and in the second, of 1550. They are gruoped together under the concept of publishers' versions (those that are introduced in the same printing presses, with the purpose of offering improved texts). Although it is very likely that some of these versions come from a courtly oral substrate, the vast majority are textual modifications made in order to offer more extensive and detailed versions. This phenomenon forces us to rethink the fragmentary nature attributed to the romancero viejo.

Keywords: romancero; prints of the Sixteenth Century; Martin Nucio;

version; rewrite.

Recepción: 7 de diciembre de 2018; aceptación: 21 de mayo de 2019.

D.R. () 2020. Nueva Revista de Filología Hispánica

Licencia Creative Commons Attribution-NonCommercial (CC BY-NC) 4.0 International 
VERSIONES, VARIANTES, REESCRITURAS*

Entre la edición que llamamos sin año del Cancionero de romances (pero con evidencia de haberse publicado hacia 1546; véase Josep Lluís Martos 2017) y su revisión de 1550, Martín Nucio no sólo modificó la distribución de los textos para agregar nuevas composiciones, sino que en algunos casos se dio incluso a la tarea de sustituir los romances primitivos con reescrituras y versiones. Aunque en principio parece una labor realizada de forma casuística, el análisis de estas reescrituras permite identificar algunos patrones que pudieron haber orientado las consideraciones editoriales de Nucio para decidirse por los textos definitivos que perdurarían en las ediciones posteriores (1550, 1555 y 1568 ).

Quizá más difícil que identificar las políticas editoriales de Nucio sea llegar a un acuerdo sobre los límites entre la reescritura y la variante o versión. Gracias a Ramón Menéndez Pidal, sabemos que el romance es "poesía que vive en variantes" (1953, p. 40) y que el sentido de sus cambios estuvo siempre orientado por los gustos de la época:

El texto de la canción, del romance, no tiene fijeza precisa e inalterable, pero sí tiene estabilidad dentro de ciertos límites. Las variantes, en su infinidad fluyente, llevan una dirección fija, determinada por el sentido general de la ficción propia de cada romance y por tendencias y gustos colectivos, de igual modo que la corriente del río está fijamente determinada por la configuración del lecho y por los obstáculos que el fondo y las orillas ofrecen (p. 43).

Sin ánimo de presentar un exhaustivo estado de la cuestión, estaremos de acuerdo en que los estudios más recientes donde se tocan estos temas no han hecho sino refrendar la validez de dicha afirmación. Desde el origen de sus tempranos estudios sobre el romancero, Diego Catalán tuvo presente la importancia de contar con un instrumental conceptual preciso; como apunta en la rectificación a un trabajo de Daniel Devoto, tras el magisterio de Menéndez Pidal, versión es "cada una de

"Este trabajo se enmarca en el proyecto "Cancionero, Romancero y Fuentes Impresas" del Ministerio de Economía, Industria y Competitividad (FFI2017-86313-P), financiado por la Agencia Estatal de Investigación (AEI) y el Fondo Europeo de Desarrollo Regional (FEDER). 
las recitaciones de un romance recogidas de la tradición oral", y variación, "todo detalle variable, sea un elemento narrativo o un simple giro de expresión, característico de una serie de versiones y desconocido de otras" (1959, p. 150, n. 3). En el campo de los estudios sobre la tradición oral moderna se aceptan bien, unas veces con matices explícitos y otras no, texto contextualizado, que se caracteriza por su variación, apertura y potencialidad (Sánchez Romeralo 1990, pp. 72 y 73-74); texto abierto de volubilidad congénita y texto proteiforme, definido por su transformabilidad (Michele Débax 1990, pp. 44, 46 y 53); versión y variante (Cid 1995, p. 52; Asensio Jiménez 2016, pp. 13-14; García Esteban 2016); variación (Aurelio González 2001, pp. 54-55). Pero esta terminología básica a menudo se enriquece con la de distintos subgéneros asociados: variación verbal y variación de la estructura temática (Catalán 1982, pp. 286-287); tanteos, variantes y rehacimientos (Bénichou 1968, p. 9); versión innovadora (Cid 1995, p. 51); versión pura (García Esteban 2016, p. 42); versión contaminada (Cid 1995, p. 60; García Esteban 2016, p. 38); versión fragmentaria (Moreno 2009, p. 256); versión trunca (Moreno 2009, p. 257); versión antigua, moderna o facticia (Valenciano 2016, pp. 320-323). En el extremo teórico de la variación estaría, por supuesto, la invariante (Do Nascimento 2001, p. 39) o el prototipo (visto con algo de desconfianza; Catalán 1982, pp. 284 y 291; Débax 1990, p. 44). En esta amplia tipología tienen cabida otras tantas estrategias de composición vinculadas a los cambios como la paráfrasis (Do Nascimento 2001, pp. 42-45); la secuencia innovadora (García Esteban 2016, p. 35); la modificación intencionada (García Esteban 2016, p. 36); y las variaciones ortotipográficas y léxicas (García Esteban 2016, pp. 36-37); la variante discursiva (Cid 1995, p. 52); la apertura en los niveles narrativo y del significado último (Cid 1995, p. 52), préstamos (Cid 1995, p. 60); fórmulas, tópicos y motivos (Aurelio González 2012, pp. 129-132). En el ámbito de los estudios sobre imprenta, también se ha estudiado la variación de los textos desde distintas perspectivas como variatio y errata (Dumanoir 2014), lógica editorial y cambio textual (Garvin 2014 y 2017) o microvariantes (Higashi 2014 y 2015).

Estas categorías (y varias más que no menciono aquí para no agotar la paciencia de quien lee) conviven con otras donde las prácticas de variación muestran intenciones deliberadas de intervención transformativa de los textos, vinculadas al ámbito de una cultura cortesana y urbana que poco tiene que ver con 
el folclor; me refiero a lo que Dumanoir ha llamado las prácticas de reescritura en el romancero viejo (1998) y que encarnan en las glosas, las contrahechuras, las deshechas y otras formas de intervención artística (Fuente Fernández 1990; Dumanoir 1998 y 2003; Díaz Mas 2000 y 2013; Piacentini y Periñán 2002 y, últimamente, Tomassetti 2017). La tipología de reescrituras también es bastante amplia, desde las reescrituras a lo divino hasta las glosas, "que no reescriben el texto, sino que reescriben alrededor del texto, a modo de comentario" (Dumanoir 1998, p. 47).

Los retos conceptuales que plantea la variación del romancero en distintos órdenes (transmisión oral, escrita, folclórica, cortesana, etc.) transparentan, sin duda, la complejidad de las prácticas. En el caso particular de la sustitución de versiones que realiza Nucio entre la primera edición del Cancionero de romances de 1546 y la segunda de 1550 , puede advertirse un afán sistemático de mejoramiento que coincide en presentar versiones más extensas y narrativamente más robustas. Eso sugiere, al menos, la nota que cerró la versión de 14 versos de "Miraua de campo viejo..." en 1546 ("Este romance esta imperfecto", f. 260r), sustituida en la nueva edición de 1550 por otra de 24 versos, donde lo más notable no es en principio la sustitución de una versión diferente por otra, sino el crecimiento de la versión primitiva por el aumento de 10 versos al final:

\begin{abstract}
MIraua de campo viejo el rey de Aragon vn dia miraua la mar de españa como menguaua y crecia mira naos y galeras vnas van y otras venian vnas cargadas de sedas y otras de ropas finas vnas van para leuante otras van para castilla mirava la gran ciudad que Napoles se dezia o ciudad quanto me costas por la gran desdicha mia
\end{abstract}

\section{Este romance esta imperfecto.}

Fin.
MIraua de campo viejo el rey de Aragon vn dia miraua la mar de España como menguaua y crecia mira naos y galeras vnas van y otras venian vnas cargadas de sedas y otras de ropas finas vnas van para Leuante otras van para Castilla miraua la gran ciudad que Napoles se dezia/ o ciudad quanto me cuestas por la gran desdicha mia. cuestas me veynte y vn años los mejores de mi vida cuestas me vn tal hermano que mas que vn Hector valia querido de caualleros 
y de damas de valia
cuestas me los mis tesoros
los que guardados tenia
cuestas me vn pagezico
que mas que a mi lo quería.

Fin.

(1550, ff. 274v-275r).

Como puede advertirse fácilmente, aunque el efecto final es de una versión corta y otra larga, no puede hablarse exactamente de dos versiones como se hace en los estudios con una perspectiva oralista, dado que las secciones coincidentes en ambos testimonios son idénticas. Como ha señalado Cleofé Tato, "Nucio, en realidad, se limitó a rellenar una laguna, y tal vez lo hizo porque, habiendo advertido la «falta» del primer texto que ofreció del romance, buscó «un exemplar» menos corrupto y completó la pieza" (1999, p. 254). En el caso de los primeros 14 vv. de la edición de 1550, los cambios más relevantes son microvariantes con un origen editorial: iniciales mayúsculas sistemáticas para los topónimos y una puntuación más densa (Higashi 2015, pp. 106-117). Si se compara con otros testimonios, como el que recoge Esteban de Nájera en la Segunda parte de la Silva de varios romances de 1550 (Beltran 2017, pp. 319-320) o la glosa en los pliegos de la Biblioteca Universitaria de Praga (Rodríguez-Moñino 1997, núm. 880), puede incluso notarse cierta independencia entre estas versiones y las de Nucio, de modo que para corregir la imperfección advertida el impresor antuerpiense no parece haber recurrido a una versión que circulara en la imprenta (como tampoco parece hacerlo Esteban de Nájera para la suya, procedente quizá de una versión glosada distinta o de algún arreglo musical, ambos localizados en la corte de Aragón; véase Beltran 2017, p. 54).

Una revisión general de las sustituciones o ampliaciones de versiones -Paloma Díaz-Mas, 2017, p. 40, las divide así en su prólogo; véase también Rodríguez-Moñino 1967, pp. 25-27demuestra que se trata de una práctica común ${ }^{1}$ :

${ }^{1}$ Suele incluirse "Tan claro haze la luna", 24vv. (1546, ff. 194v-195r) / "A tan alta va la luna", 38 vv. (1550, ff. 205v-206r), pero se trata de romances distintos que coinciden nada más en su incipit. Parece evidente que quien realizó la sustitución (el mismo Nucio o cualquiera de sus operarios) no leyó el romance y sólo se fijó en su extensión algo mayor, de modo que el romance del conde Alemán se presentó bajo el título (repetido en la cornisa del f. 206r) de "Romance de Baldouinos", conservando la ubicación original 
1. "En sancta Gadea de Burgos", 68vv. (1546, ff. 153v-155r). / "En sancta Agueda de Burgos", 80 vv. (1550, ff. $156 \mathrm{v}-158 \mathrm{r})$.

2. "Cada dia que amenece", 34 vv. (1546, ff. 155r-155v). / "Dia era delos Reyes", 78 vv. (1550, ff. 162r-163r).

3. "Doliente estaua doliente", 16 wv. (1546, ff. 157v-158r). / "Doliente se siente el rey", 24 vv. (1550, ff. 146r-146v).

4. "Morir vos queredes padre", 34 vv. (1546, ff. 158r-158v).

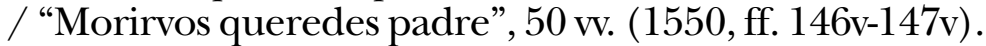

5. "Por aquel postigo viejo", $30 \mathrm{vv}$. (1546, ff. 159r159v). /

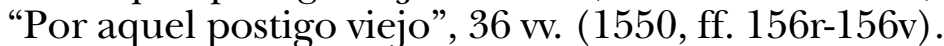

6. "Tres cortes armara el rey", 36 w. (1546, ff. 160v-161v). / "Tres cortes armara el rey", 71 vv. (1550, ff. 164v-165v).

7. "Yo me estaua en baruadillo", 26 w. (1546, ff. 163v-[164]r). / "A Calatraua la uieja", 138 vv. (1550, ff. 170r-172v).

8. "En essa ciudad de burgos", 84 vv. (1546, ff. 177v-179r y 1550, 185v-186v). / "En Burgos esta el buen rey", 188 vv. (1550, ff. 295v-298v).

9. "Abenamar Abenamar", 52 vv. (1546, ff. 182v-183v). / "Por Guadalquiuir arriba", 84 vv. (1550, ff. 191r-192v).

10. "Por la matança va el viejo", $44 \mathrm{vv}$. (1546, ff. 188r-188v). / "En los campos de Aluentosa", 80 vv. (1550, ff. 198r-199v).

11. "A Caçar va el cauallero", 34 vv. (1546, ff. 192r-192v). / "A Caçar va el cauallero", 50 vv. (1550, ff. 203r-203v).

12. "QVien vuiesse tal ventura", 26 vv. (1546, ff. 192v-193r). / "QVien vuiesse tal ventura", 36 vv. (1550, ff. 203v-204v).

13. "Bien se pensaua la reyna", 24 vv. (1546, ff. 227r-227v). / "Bien se pensaua la reyna", 38 vv. (1550, ff. 240v-241r).

14. "Esperança me despide", 24 vv. (1546, ff. 250r-250v). / "Esperança me despide", 17 vv. (1550, f. [264r]).

15. "POr el mes era de Mayo", 14 vv. (1546, ff. 251r). / "POr el mes era de Mayo", 40 vv. (1550, ff. 265r-266r).

16. "O Belerma, o Belerma”, 44 vv. (1546, ff. 254v-255v). / "O Belerma, o Belerma", 64 vv. (1550, ff. 269v-270v).

17. "Miraua de campo viejo", 14 vv. (1546, ff. 260r). "Miraua de campo viejo", 24 vv. (1550, ff. 274v-275r).

18. "La triste reyna de Napoles", 26 vv. (1546, ff. 262v-263r). / "Emperatrizes y reinas", 54 vv. (1550, ff. 277v-278v).

entre los romances de "Cata Francia Montesinos / cata Paris la ciudad" y "Por una linda espessura / de arboleda muy florida". He podido tratar el tema más por extenso en HigAsHi, en prensa. 
"AÑADIDO EN MUCHAS PARTES":

MARCOS NARRATIVOS, DESENLACES, INCRUSTACIONES

Un primer patrón de mejoramiento, como puede verse en el listado anterior, fue la ampliación de los textos por medio de reescrituras 2 : Rodríguez-Moñino los denomina textos mejorados e incluye aquellos en los que se añade desde un par de octosílabos $^{3}$ hasta una veintena ${ }^{4}$; cuando las ampliaciones exceden estos límites, se refiere a "cambio radical de textos" -aunque, como veremos, no en todos los casos podemos estar de acuerdo con él ${ }^{5}$. Recientemente, Paloma Díaz-Mas (2017, pp. 40-42) se refiere, con un mejor criterio, a sustituciones ${ }^{6}$ y ampliaciones $^{7}$.

Estos romances se presentan en reescrituras ampliadas conforme a distintos patrones, lo que indica que la idea de mejoramiento de Martín Nucio estaba estrechamente ligada al mero acto de sumar versos, sin importar mucho que fuera al principio, al medio o al final de los romances. Esta base meramente cuantitativa resulta consecuente con la incorporación de 30 romances nuevos en 1550 (Garvin 2007, p. 221; RodríguezMoñino 1967, p. 27) por la eliminación de cuatro romances y de los espacios en blanco que resultaban de terminar en 1546 la fuente impresa de la que se copiaba (por lo regular un plie-

${ }^{2}$ En la lista, "Esperança me despide" parece a primera vista una excepción (donde la versión primitiva de $24 \mathrm{vv}$. pasó a otra de $17 \mathrm{vv}$.), pero no hay que perder de vista que en 1550 se conservan, de forma consecutiva, tanto la versión de 24 vv. como la nueva de 17 v. Si se suman las dos versiones, como en los otros casos, se añadió texto.

${ }^{3}$ En "Después que Vellido Dolfos" se agrega el v. 17; en "Afuera, afuera Rodrigo", 2 vv. entre 8-9 de 1546; en "Castellanos y leoneses", 2 vv. entre 13-14; en "Buen conde Fernán González", 4 vv. entre 12-13 y otros 2 vv. entre 32-33; en "Nuño Vero, Nuño Vero", 2 vv. entre 16-17 y otros 2 entre 20-21 (RoDRíguez-MoÑIno 1967, pp. 25-27).

4 "QVien vuiesse tal ventura", "Bien se pensaua la reyna", "POr el mes era de Mayo", "O Belerma o Belerma" y "Miraua de campo viejo" (RodRÍGUEZ-MoÑINo 1967, pp. 25-27).

${ }^{5}$ Divide los nueve casos entre los que tienen el mismo comienzo ("Doliente estaua doliente", "Morir vos queredes padre", "Por aquel postigo viejo", "Tres cortes armara el rey" y "Esperança me despide") y aquellos que no ("En sancta Gadea de Burgos" / "En sancta Agueda de Burgos", "Por la matança va el viejo" / "En los campos de Aluentosa", "Tan claro haze la luna" / "A tan alta va la luna" y "La triste reyna de Napoles" / "Emperatrizes y reinas".

${ }^{6}$ Los enlistados en la nota anterior.

7 Varios de los enlistados en las notas 3 y 4. 
go suelto) al final del último romance y comenzar el siguiente en el recto o verso del folio (Higashi 2013, p. 59, y 2015, p. 93).

La búsqueda de versiones más completas contradice -o al menos matiza desde la perspectiva de los gustos de la época reflejados en la oferta de los impresores- la idea de Menéndez Pidal sobre el gusto por el fragmentismo en el romancero viejo, según la cual se "tiende a prescindir de preliminares, incidentes o desenlace, para destacar sólo una situación elegida, o una rápida serie de sucesos nucleares" (1953, p. 71). Considerada por Menéndez Pidal como un rasgo de identidad del romancero hispánico ${ }^{8}$, celebra en varias partes su poder evocador y su superioridad sobre la simple descripción, como cuando señala en referencia a la versión corta del Conde Arnaldos que "en ella la simple fragmentación es un todopoderoso acto creador, desbordamiento de lirismo que infunde en los versos viejos una poesía nueva de incalculable virtualidad" (p. 74) y que, ya en referencia a otros romances, "cualquier desenlace preciso sería un descenso, una caída” (p. 75). Añadirá en nota que Milá y Fontanals pensaba que "el fragmento, haciéndonos adivinar el todo, nos mueve más que el todo mismo" (p. 75, n. 22).

La evidencia ofrece conclusiones muy distintas si enfocamos el fenómeno desde la perspectiva de un impresor atento a la demanda de su público y cuyo proyecto de mejoramiento del Cancionero de romances muestra al menos tres etapas distintas (en 1546, la recopilación; el perfeccionamiento ortotipográfico y editorial en general en 1550; la regularidad métrica en 1555; véase Higashi 2015). Para Nucio, la mejor versión era la más completa y articulada. Como apuntaba Giuseppe di Stefano en una de las primeras reflexiones dedicadas a este tema, "è assai probabile che poco entusiasmo suscitassero in lui le romanze a struttura aperta, i comunissimi «frammenti»" (1968, p. 165). Rodríguez-Moñino coincidió con Nucio cuando afirmó que "a nuestro juicio, casi siempre son mejores los textos de 1550 que los antiguos" (1967, p. 27).

Este gusto por las obras más extensas y con más detalles, con una narrativa más redonda, coincide con el auge de otro género cercano fraguado con éxito en el quinquenio que va de 1546 a 1551, cuando florece el romancero historiado en colecciones de autor realizadas expresamente sobre fuentes librescas, tan-

8 Como apunta, "en conjunto, los romances fragmentarios constituyen la más típica porción del romancero viejo” (1953, p. 333). 
to en Amberes como en la Península, al estilo de los Romances nuevamente sacados de historias antiguas de la crónica de España de Lorenzo de Sepúlveda o el libro de los Quarenta cantos de Alonso de Fuentes (véase Higashi 2018, pp. 75-113); sin olvidar, por supuesto, el protagonismo del romancero historiado y religioso, ambos de raigambre culta, en las tres partes de la Silva de varios romances de Esteban de Nájera, bien estudiado por Vicenç Beltran (2017, pp. 160-161).

\section{LA POÉTICA DEL ROMANCE $A \tilde{N} A D I D O$ : LOS FINALES}

En la observación de "Este romance esta imperfecto" (1546, f. 260r), quizá lo que más llame la atención sea la conciencia que muestra Nucio respecto de lo que sería una forma perfecta o imperfecta. Como se recordará, ya desde el prólogo de 1546 se había referido a ello cuando afirma que no fue poco trabajo "juntarlos y enmendar y añadir algunos que estauan imperfectos" (1546, ff. A1v-A2r). En la nueva edición de 1550, desde su portada se anuncia que se publica "nueuamente corregido emendado y añadido en muchas partes". "Añadido en muchas partes" podría ser una certera alusión a un número apreciable de romances intervenidos $-\mathrm{y}$ no a los nuevos, como siempre se ha entendido. El uso de añadido en el sentido de un romance intervenido y completado ya está presente desde la primera edición del Cancionero de romances en el título de "Triste estaua el cauallero" ("Romance añadido por Quiros desde donde dize que es de ti señora mia", 1546, f. 242v) y se usa como sinónimo de acabado ("Romance acabado por Quiros desde donde dize mi vida quiero hazer", 1546, ff. 243r-243v, y "Otro romance viejo acabado por don Alonso de cardona / desde donde dize. Con lagrimas \& sospiros", 1546, ff. 236v-237r, también sobre "Triste estaua el cauallero"). Sobra agregar que se trata de un uso también conocido por los pliegos sueltos ("Este romance añadio quiros...", "Otro romance viejo haste donde dize mi vida quiero hazer \& de ay adelante hizo quiros”, Rodríguez-Moñino 1997, núms. 658, 668 y 1170).

A juzgar por la orientación de la enmienda en "Miraua de campo viejo", el romance se perfeccionaría con la suma de 10 versos más, sin realizar ninguna otra corrección de peso a lo ya publicado con anterioridad. Para Nucio, como ha señalado Giuseppe di Stefano, "i suoi interventi di correttore del singolo tes- 
to e di ordinatore sono orientati verso l'istituzione di strutture chiuse, verso un romance-cuento tematicamente e formalmente conchiuso" (1968, p. 165). Esta idea no parece privativa de Nucio, si consideramos que la versión transmitida por Esteban de Nájera tiene $34 \mathrm{vv}$. -es decir, $10 \mathrm{vv}$. más que la ampliada de Nucio; véase Beltran 2017, pp. 50-54.

Sucede igual con "Bien se pensaua la reyna", sin variantes entre los vv. 1-24 conservados en 1546 y 1550 -más allá de microvariantes como las mayúsculas de Galván y de Castilla-, pero con un añadido final de $14 \mathrm{vv}$. donde se narra el ascenso a la torre, el parto repentino y la entrega del recién nacido a Galván, lo que redondea la anécdota contada en la primera versión:

$$
\begin{aligned}
& \text { subiera se la infanta } \\
& \text { a lo alto de vna torre } \\
& \text { si bien labraua la seda } \\
& \text { mejor labraua el retros } \\
& \text { vido venir a Galuan } \\
& \text { telas de su coraçon } \\
& \text { Ellas en aquesto estando } \\
& \text { el parto le tomo } \\
& \text { ay por dios ay mi señor } \\
& \text { allegueys os a essa torre } \\
& \text { recogedme este mochacho } \\
& \text { en cabo de vuestro manto } \\
& \text { dedes me lo a criar } \\
& \text { a la madre que os pario } \\
& \text { (1550, f. 241r). }
\end{aligned}
$$

En "Tres cortes armara el rey" (1546, ff. 160v-161v; 1550, ff. $164 \mathrm{v}-165 \mathrm{v}$ ), también concuerdan en todo las dos versiones (con las escasas microvariantes esperadas: burgos/Burgos, leon/Leon, toledo/Toledo, quel/qu'el) hasta el v. 32, donde se incrusta una amplificación suntuaria:

todos hijos dalgo son

todos vestidos de vn paño

de vn paño y de vna color

sino fuera el buen Cid

que traya vn albornoz todos hijos dalgo son

todos vestidos de vn paño de vn paño y de vna color sino fuera el buen Cid que traya vn albomoz el albornoz era blanco parecia un emperador capacete en la cabeca 
mantenga vos dios el rey

(1546, ff. 161r-161v). que relumbra como el sol mantenga vos dios el rey

$(1550$, f. 165r).

El romance en 1546 termina de forma trunca en el v. 36 ("que no hablo yo alos condes / que mis enemigos son"), pero en 1550 se añaden 31 octosílabos que contradicen la última indicación con un diálogo mediado por el rey, en el que los infantes de Carrión alegan merecimientos ("Alli dixeron los condes...") y el Cid, siempre dirigiéndose al rey, los refuta ("Alli hablara el buen Cid...”). Como apunta Mario Garvin (2007, pp. 227-228), esta ampliación refleja el deseo del impresor por completar un romance que percibía como imperfecto.

Se procede igual en "A Caçar va el cauallero" (1546, ff. 192r-192v; 1550, ff. 203r-203v), donde a un romance de $36 \mathrm{vv.}$ copiado con fidelidad absoluta -sólo se corrige un tipo volcado: causados/ cansados- se agregan $16 \mathrm{vv}$. En el conjunto inicial, la infantina pide al caballero la lleve a la corte, "si quisieres por muger / sino sea por amiga"; el caballero expresa sus dudas y avisa que consultará a su madre; el romance concluye con la maldición de la niña ("o mal aya el cauallero / que sola dexa la niña / el se va a tomar consejo / y ella queda en la montina"). Sobra decir que los versos añadidos completan la anécdota trunca: ahora se explicita el consejo de la madre -en referencia a los wv. 27-28- y las consecuencias de no haber hecho caso a la infantina desde el principio -el caballero ve cómo se llevan a la niña y se autoinflige un severo castigo por no haberla llevado él-:

Aconsejo le su madre que la tomasse por amiga quando boluio el cauallero no hallara la montina vido la que la lleuauan con muy gran caualleria. El cauallero desque la vido en el suelo se caya. de desque en si vuo tornado estas palabras dezia.

Cauallero que tal pierde muy gran pena merescia yo mesmo sere el Alcalde yo me sere la justicia 
que le corten pies y manos

y lo arrastren por la villa

(1550, f. 203v, vv. 35-50).

La intención de entregar un romance más perfecto sugiere a Nucio prolongar y redondear la historia original. Hasta aquí, no hay misterio. Lo interesante son las estrategias de mejoramiento: por un lado, la meticulosa conservación del núcleo original y, por el otro, la continuidad y cierre que el añadido ofrece al romance primitivo son movimientos contrarios que sugieren una intencionalidad consciente y solidaria. Se trata de coletillas que desprovistas del romance que les antecede no tienen sentido y que difícilmente pudieron tener vida propia fuera del circuito de los gustos de su público por los detalles narrativos y los finales cerrados. Coletillas que incluso se oponen a la estética típica del romance glosado, breve y sugerente precisamente para justificar la glosa de que se acompañaba. La cerrada coincidencia entre los textos de las dos versiones permite suponer que los añadidos fueron solicitados expresamente por Nucio a algún autor anónimo dispuesto a remendar romances. Esta forma de proceder no extraña si se tiene en cuenta el naciente gusto por romances más redondos y robustos desde el punto de vista narrativo por esos mismos años. Lorenzo de Sepúlveda, con el respaldo de la crónica ocampiana, compondría todo un romancero en el que se expresaba continuamente el prestigioso valor ejemplar de la historia antigua, con la clara intención de ser sus romances un reflejo de ella en sus indicios y en la complejidad de la anécdota (Higashi 2018, pp. 20-24). Alonso de Fuentes, en un camino muy cercano, no dudaría en respaldar su prestigio en llamar cantos a estos romances para ponerlos de un plumazo a la altura de los cantos homéricos y de la naciente poesía épica del período, al estilo de la traducción de Jerónimo de Urrea del Orlando furioso publicada en 1549 (Higashi 2018, pp. 28-29).

LA POÉTICA DEL ROMANCE AÑADIDO: INCIPIT E INCRUSTACIONES

En los 26 vv. de "Yo me estaua en baruadillo" (1546, ff. 163v[164]r), doña Lambra se lamenta por las ofensas de los infantes de Lara y don Rodrigo promete vengarla en un romance 
que es ejemplo típico del fragmentismo del romancero viejo. En la segunda edición (1550, ff. 170r-172v), se añade un largo prólogo ("A Calatraua la uieja") de 112 vv. para enmarcar este diálogo inicial. De nuevo, las escasas microvariantes entre 1546 y 1550 (baruadillo/ Baruadillo; castilla/ Castilla; me an/ me han; palomar/ Palomar, mora/ Mora; alli/ Alli; calledes/Calledes; salas/ Salas) sugieren más bien pensar en una ampliación que en dos versiones distintas (al menos, considerado el fenómeno desde la perspectiva del mismo impresor). Sin poder afirmar con certeza la procedencia de este extenso prólogo que sirve de marco, pues no se conoce por otras fuentes anteriores, podemos ver en su factura y conservación a lo largo de las ediciones siguientes el interés que despertaban ya las historias más completas y articuladas del romancero historiado. En este caso, a diferencia todavía de lo que hará Sepúlveda cuando componga sus romances de principio a fin sobre la base de la información contenida en la crónica ocampiana, nos encontramos delante de un híbrido donde el núcleo de esta inserción de 112 vv. será un romance conocido desde hacía varios años por la tradición -el típico lamento femenino in medias res respondido por don Rodrigo, glosado por Luis Peralta y contrahecho por Diego de San Pedro; véase Garvin 2007, p. 198-, inserto ahora en un marco que explicita las circunstancias contextuales nada más sugeridas en el núcleo primitivo.

¿El que este marco no se conserve en otros testimonios impresos o manuscritos previos ni tampoco de forma independiente al Cancionero de romances sugiere que pudo haberse compuesto de forma deliberada para esta edición de 1550 ? $\mathrm{Si}$ así fuera, este romance representaría una primera tentativa de composición alrededor de un núcleo de probable transmisión folclórica, pero que al llegar a los circuitos de distribución impresa encontró poetas interesados en continuar la intriga con alguna libertad. En todo caso, esta intención de reescribir, citar y reinterpretar un texto antiguo tenía mucha semejanza con la forma de proceder desde hacía varias décadas al glosar los romances.

En "Abenamar Abenamar" (1546, ff. 182v-183v) o "Por Guadalquiuir arriba" (1550, ff. 191r-192v), las versiones difieren de nuevo por algunas apostillas incrustadas en diferentes secciones del arranque del romance. La primera está al inicio (vv. 1-6) de 1550 y enmarca narrativamente el diálogo original ("Por Guadalquiuir arriba / el buen rey don Iuan camina / encontrara 
con vn Moro / que Abenamar se dezia. / El buen Rey desque lo vido / desta suerte le dezia”). Después de los vv. 1-2 de 1546 ("Abenamar Abenamar / moro dela moreria"), se incrusta una nueva apostilla sobre la genealogía de Abenamar y su obligación de decir la verdad:

\begin{tabular}{l} 
hijo eres de vn Moro perro \\
y de vna Christiana catiua \\
a tu padre llaman Hali \\
y a tu madre Catalina \\
quando tu nasciste Moro \\
la luna estaua crecida \\
y la mar estaua en calma \\
viento no la rebullia \\
Moro que en tal signo nasce \\
no deue dezir mentira \\
preso tengo vn hijo tuyo \\
yo le otorgare la vida \\
si me dizes la verdad \\
de lo que te preguntaria \\
Moro sino me la dizes \\
a ti tambien mataria \\
yo tela dire buen rey \\
si me otorgas la vida \\
digas me la tu el Moro \\
que otorgada te seria \\
\multicolumn{1}{c}{$(1550$, f. $191 \mathrm{v})$. }
\end{tabular}

La otra apostilla se ancla sobre la maestría del campesino para labrar las dehesas de la Alhambra, que gana cien doblas al día; el contenido es claramente redundante y amplificatorio, agregado simplemente para alimentar el gusto por los detalles:

los otros lo alixares labrados a marauilla el moro que los labro cien doblas ganaua al dia

\author{
los otros lo Alixares \\ labrados a marauilla \\ el Moro que los labro \\ cien doblas ganaua al dia \\ y el dia que no los labra \\ delo suyo las perdia \\ desque los tuuo labrados \\ el rey le quito la uida \\ porque no labre otros tales \\ al rey del Andaluzia
}


la otra era granada

Granada la noblecida

$(1546$, f. 182v). la otra era Granada

Granada la noblecida

$(1550$, f. 192r).

La idea de un poder real ejecutor ("Moro sino me la dizes / a ti tambien mataria" y "desque los tuuo labrados / el rey le quito la uida") que subyace en ambas secciones sugiere que proceden de un mismo impulso creativo. El resto del texto de ambos romances coincide puntualmente, salvo en las microvariantes esperadas -en su mayoría, mayúsculas después de puntuación, más regular en 1550: alli/ Alli; granada/ Granada; casada/ Casada; mora/ Moro; echen/ Echen; tiraremos/ Tiraremos; el/ El; los castellanos/Los Castellanos; a/ ha; castilla/ Castilla.

En "Por la matança va el viejo" (1546, ff. 188r-188v) y "En los campos de Aluentosa" (1550, ff. 198r-199v), se inserta un marco al principio ${ }^{9}$, se amplifica el listado de maldiciones del padre ${ }^{10}$ y otro par de secciones más (v. 49-50 y 73-80 de 1550). La sección inicial sufre algunos cambios que no pueden clasificarse como reescrituras en el sentido estricto. Ante la incongruencia lógica de 1546 (vv. 1-16; el padre busca el cadáver del hijo primero, pero hasta después sabemos que echó suertes, perdió y tuvo que regresar a buscarlo), en la versión de 1550 se restituye la coherencia lógico-causal (su padre echa suertes y pierde, regresa al campo de batalla, voltea los cadáveres para encontrar a su hijo, ve a todos los franceses y no lo halla):

1546:

A)

POr la matança va el viejo por la matança adelante los braços lleua cansados
1550 :

C1)

siete vezes echan suertes quien lo boluera a buscar;

9 Se agrega un incipit sobre la muerte de don Beltrán que explica el móvil del romance ("EN los campos de Aluentosa / mataron a don Beltran / nunca lo echaron menos / hasta los puertos passar", vv. 1-4 de 1550).

${ }^{10}$ En la versión de 1550: "maldiziendo yua el vino / maldiziendo yua el pan / el que comian los Moros / que no el de la Christiandad / maldiziendo yua el arbol / que sola en el campo nasce / que todas las aues del cielo / alli se vienen a assentar / que de rama ni de hoja / no la dexauan gozar / maldiziendo yua el cauallero / que caualgaua sin page / si se le cae la lança / no tiene quien se la alçe / y si se le cae la espuela / no tiene quien se la calçe / maldiziendo yua la muger / que tan solo vn hijo pare / si enemigos se lo matan / no tiene quien lo vengar" (vv. 23-42). 
delos muertos rodear no hallaua al que busca ni menos la su señal;

B)

vido a todos los franceses y no vido a don beltran;

\section{C1 y 2)}

siete vezes echan suertes quien le boluera a buscar echan las tres con malicia las quatro con gran maldad;

D)

todas siete le cupieron al buen viejo de su padre;

E)

buelue riendas al cauallo y el se lo buelue a buscar de noche por el camino de dia por el xaral.
D)

todas siete le cupieron al buen viejo de su padre;

C2)

las tres fueron por malicia y las quatro con maldad;

E) buelue riendas al cauallo y buelue se lo a buscar de noche por el camino de dia por el xaral /

A)

Por la matança va el viejo por la matança adelante los braços lleua cansados delos muertos rodear / no hallaua al que busca ni menos la su señal;

B)

vido todos los Franceses y no vido a don Beltran.

La intervención tiene el propósito de restablecer una coherencia lógico-causal, con el dístico como unidad básica. Estos cambios amplían la nómina de procedimientos a las mejoras de la lógica narrativa. No sólo se amplía y aclara, sino que se perfecciona el orden narrativo mediante el reacomodo de algunos dísticos. Esta capacidad de recreación se explicita en la contrahechura que le siguió desde 1546, con el siguiente título: "Otro romance contrahaziendo el de arriba mudado en otro proposito y fundado sobre la yda de vn cauallero a curarse con el palo delas Indias" (1546, f. 189r); sobre decir que los arreglos de 1550 se limitan al romance que sirve de modelo y obvian cualquier posibilidad de mejora en la contrahechura que pasa tal cual a 1550.

Aunque se dificulta referirse a dos versiones distintas, dado que la de 1550 parece un arreglo en la imprenta de la de 1546 , es cierto que puede advertirse aquí y allá pequeñas mejoras estilísticas y otro par de incrustaciones en el resto del texto: 
enla entrada de vn prado saliendo de vn arenal vido estar en esto vn moro que velaua en vn adarue hablo le en algarauia como aquel que bien la sabe

cauallero de armas blancas si lo viste aca passar y si le tienes preso moro a oro te le pesaran y si tu le tienes muerto des me lo para enterrar porque el cuerpo sin el alma muy pocos dineros vale esse cauallero amigo dime tu que señas $h a$ armas blancas son las suyas y el caballo es alazan $y$ enel carrillo derecho el tenia vna señal que siendo niño pequeño se la hizo vn gauilan esse cauallero amigo muerto esta en aquel pradal dentro del agua los pies y el cuerpo en $v$ arenal siete lançadas tenia passan le de parte a parte (1546, ff. 188r-188v).
Ala entrada de vn puerto saliendo de vn arenal vido enesto estar vn Moro que velaua en vn adarue hablo le en Algarauia como aquel que bien la sabe por dios te ruego el Moro me digas vna verdad.

Cauallero de armas blancas si lo viste aca passar y si tu lo tienes preso a oro telo pesaran y si tu lo tienes muerto des me lo para enterrar pues que el cuerpo sin el alma solo vn dinero no vale esse cauallero amigo dime tu que señas trae, armas blancas son las suyas y el caballo es alazan enel carrillo derecho el tenia vna señal que siendo niño pequeño se la hizo vn gauilan este cauallero amigo muerto esta en aquel pradal las piernas tiene enel agua y el cuerpo en $e l$ arenal siete lançadas tenia desde el ombro al carcañal y otras tantas su caballo desde la cincha al pretal no le des culpa al cauallo que no se la puedes dar que siete vezes lo saco sin herida y sin señal y otras tantas lo boluio con gana de pelear

$(1550$, ff. 199r-199v).

En el romance del conde Arnaldos ("QVien vuiesse tal ventura", 1546, ff. 192v-193r; 1550, ff. 203v-204v), se suman $10 \mathrm{vv.}$ al romance primitivo de $26 \mathrm{vv}$, conservado con escasas microvariantes (nel mastel/ enel mastel; las faz posar/ las faze), entre los vv. 18-19. La inserción corresponde a la canción aludida al final 
del romance, una invocación de protección a la propia galera ("yo no digo esta cancion / sino a quien conmigo va"):

\author{
galera la mi galera \\ dios te me guarde de mal \\ de los peligros del mundo \\ sobre aguas de la mar \\ de los llanos de Almeria \\ del estrecho de Gibraltar \\ y del golfo de Venecia \\ y de los bancos de Flandes \\ y del golfo de Leon \\ donde suelen peligrar
}

(1550, f. 204r).

Desde Menéndez Pidal y hasta Cesare Segre (véase López Guil 2006, pp. 69-77), este romance ha sido uno de los ejemplos emblemáticos de la naturaleza programática del fragmentismo en el romancero, y ahí el romance de 1546 ha sido erigido como el más incompleto de todos. Amén de la defensa que hace Itzíar López Guil de la versión corta como un texto "programáticamente abierto", en su argumentación subyace la idea de estar frente a un texto oral cuyas zonas de indeterminación estimularon naturalmente la veta creativa de los autores e impresores de la época; es decir, la versión corta no se amputó en la tradición impresa, sino que más bien se completó en su camino posterior de imprenta a imprenta.

En "Por el mes era de Mayo" (1546, f. 251r; 1550, ff. 265r-266r), ambos textos coinciden en sus primeros $14 \mathrm{vv}$. (salvo por una errata en 1546 que corrige 1550: vallestro/ valleste$r o$ ), pero los versos que se suman en 1550 dan la impresión de ser paródicos (sigo a Giuseppe di Stefano 2010, pp. 178-179). Otra vez, no puede hablarse de una nueva versión, sino de un núcleo narrativo que se apostilla con una orientación paródica -la cárcel de amor del primer núcleo narrativo se convierte en una cárcel de verdad, con un desenlace jocoso donde el reo, caricaturizado para sugerir el paso del tiempo, pretende esconder una lima sorda en una empanada-; estamos delante de un buen ejemplo de reinterpretación del romance primitivo, voluntaria o involuntaria, en un sentido contrario al de su factura original (de índole netamente amorosa), gracias a una coletilla: 
cabellos de mi cabeça

llegan me al coruejon los cabellos de mi barba

por manteles tengo yo

las uñas delas mis manos

por cuchillo tajador

si lo hazia el buen rey

hace lo como señor

si lo haze el carcelero

hacelo como traydor

mas quien agora me diesse

vn paxaro hablador

si quiera fuesse calandria

o tordico o ruyseñor

criado fuesse entre damas

y abezado ala razon

que me lleve vna embaxada

mi esposa Leonor

que me embie vna empanada

no de trucha mi salmon

sino de vna lima sorda

y de vn pico tajador

la lima para los hierros

y el pico para la torre

oydolo auia el rey

mandole quitar la prisión.

Fin.

$$
\text { (1550, ff. 265v-266r). }
$$

Miguel Ángel Pérez Priego ha dejado apuntada la dificultad de trazar una cronología de la génesis en estas dos versiones, aunque apunta que lo más lógico sería el crecimiento de la versión corta (2013, pp. 265-266); en todo caso, opina que había un romance-escena (el prisionero y la muerte de la avecilla) al que se le añadió un romance-cuento (el plan para salir de prisión) que "rebajaba los valores líricos conseguidos en la primera" (2013, pp. 268-269).

El procedimiento, pese a todo, no es uniforme. En "Doliente estaua doliente" (1546, ff. 157v-158r; 1550, ff. 146r-146v), alternan dos versiones de procedencia distinta -lo que incluso afectó el incipit del romance-y el final añadido es en realidad un enlace con el romance siguiente ("Morir vos queredes padre") (Garvin 2007, pp. 225-226). Este enlace pudo proceder de la misma imprenta de Nucio, pero no puede descartarse que 
Nucio lo haya encontrado así en una fuente previa, ya que se trataba de un procedimiento más o menos común (véase Higashi 2012, pp. 522-526). Las variantes, en todo caso, traslucen dos versiones que difieren en el léxico, el orden de las palabras en el octosílabo, el añadido de un par de octosílabos y esta coletilla editorial de enlace con el siguiente romance:

DOliente estaua doliente esse buen rey don Fernãdo los pies tiene cara oriente y la candela enla mano ala cabecera tiene

los sus fijos todos quatro los tres eran dela reyna y el vno era bastardo esse que bastado era quedaua mejor librado arçobispo es de Toledo

y enlas españas perlado si yo no muriera hijo vos fuerades padre santo mas con la renta que os queda bien podreys hijo alcançarlo.
DOliente se siente el rey 1550

hazia oriente 1550

a su cabecera 1550

arçobispos y perlados

a su manderecha tiene $a d d .1550$ a sus fijos 1550

maestre de Santiago abad era en çaragoça $a d d .1550$ delas España primado 1550 Hijo si yo no muriera 1550

vos bien podreys alcançarlo 1550 Ellos estando en aquesto entrara Vrraca Fernando y buelta hazia su padre desta manera ha hablado add. 1550

Pese a las diferencias, el último agregado de 4 vv. con el propósito de unir este romance y el siguiente demuestra el derecho que se arrogaban los impresores para hacer algunos ajustes; aunque conocemos bien la labor de zurcir y remendar versos del teatro (véase, por ejemplo, Rodríguez López-Vázquez 2000, pp. 26-30), es muy poco lo que sabemos de los arreglos en la imprenta (por ejemplo, González Ramírez 2011). Los casos analizados en la imprenta de Nucio nos ofrecen, por primera vez, una buena oportunidad para acercarnos a este mundo de obras anónimas que podían ser manipuladas por los impresores, siempre cobijados por la intención de mejorar los textos. Puede pensarse, sin duda, que exagero al referirme a reescri- 
turas dentro de las imprentas, pero no se olvide que Nucio en su compilación, y más de una vez, ofrece ejemplos señeros de reescrituras y recortes editoriales cuando sistemáticamente despoja de sus glosas a los romances seleccionados para incluirlos en su colección. Si algo caracteriza al Cancionero de romances de 1546 es precisamente su capacidad para arriesgarse y adelantarse a los gustos del público de la segunda mitad del siglo XVI al dejar atrás los romances glosados. Si en un primer momento el ejercicio de glosar los romances resultó fundamental para aclimatar esta forma folclórica al público de las cortes, primero, y de las ciudades, después (Beltran 2016), el público que se consolidaba en el quinquenio 1546-1551 alrededor de esta iniciativa de Nucio o de otros impulsos semejantes, como los Quarenta cantos de Alonso de Fuentes o los Romances nueuamente sacados de historias antiguas dela cronica de España de Sepúlveda, habría de disfrutar naturalmente del romance por sí mismo -de un romance, claro, robustecido por la participación, ahora sí, de autores que firmaban sus obras y demostraban que el género podía adaptarse a estos nuevos públicos. En todo caso, como en su momento señaló Ramón Menéndez Pidal:

El Canc. s. a. acogió en sí estas dos colecciones [se refiere al Cancionero general de Hernando del Castillo y al conjunto de pliegos sueltos]; pero, especializado rigurosamente, se interesó tan sólo por el romance, y rechazó los adornos con que hasta entonces solía imprimirse. Así, de los romances que tomó del Canc. Gral. y de los pls. ss. eliminó todas las glosas hechas a los romances populares o popularizados, y suprimió así mismo las desechas, villancicos y metros varios con que se adornaban los romances artísticos, dejando pasar muy pocas excepciones (1945, p. xlv).

Estos versos de enlace nos ponen sobre la pista del patrón que subyace a los núcleos narrativos añadidos antes, en su mayoría desconocidos en fuentes anteriores a la compilación de Nucio. Frente a una nueva edición, la tentación de añadir algunos textos para cumplir con la promesa del prólogo fue mucha; en todo caso, en la imprenta de Nucio parece haberse sucumbido a ella.

El exordio (A) que se agrega al final de "Doliente estaua doliente" (Garvin 2007, p. 226) adelanta el tipo de añadidos a "Morir vos queredes padre" (1546, ff. 158r-158v; 1550, ff. $146 \mathrm{v}-147 \mathrm{v}$ ): el primero (B) enmarca la respuesta del rey y le da la palabra a su hija Urraca; el segundo (C) narra el cerco 
de Zamora por Sancho y el Cid (como una explicación al dístico con que concluye 1546, "todos dizen amen amen / sino don Sancho que calla"), y el tercero de nuevo adelanta el exordio (D) para volverle a dar la palabra a Urraca y pie al siguiente romance ("Afuera afuera Rodrigo"). Sobra decir que entre las secciones conservadas en 1550 apenas pueden espigarse las pocas microvariantes de rigor (miguel/ Miguel; vras/ vuestras; castilla/ Castilla; vizcaya/ Biscaya; moros/Moros; christianos/Christianos; calledes/Calledes; duero/ Duero):

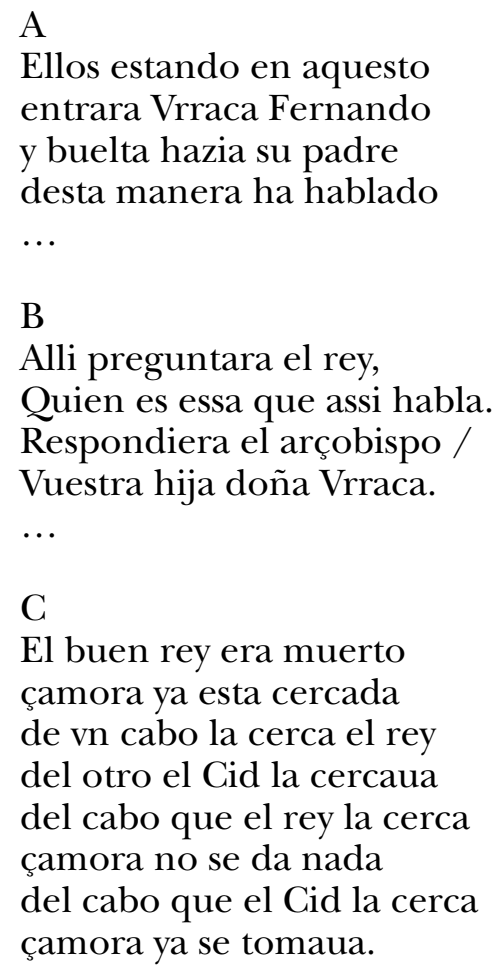

Los cambios aquí descritos no pueden concebirse como eventos aislados; al contrario, forman parte de un plan en el que los romances en 1550 se insertan en una macrosecuencia 
gracias al zurcido inteligente de versos, romance tras romance. La secuencia de romances-escenas donde los parlamentos de los personajes se suceden yuxtapuestos con cierta confusión parece haber justificado estas incrustaciones editoriales, pensadas en su mayoría para explicitar los turnos de habla y fortalecer la idea de un romance-cuento. Desprovistos de sus respectivas glosas, estos textos breves fueron añadidos y mejorados por el impresor desde la perspectiva de una narrativa tradicional: más completa y mejor construida.

No todos los añadidos tienen la intención de dilatar la narración o zurcir romances afines. En el caso de "Por aquel postigo viejo" (1546, ff. 159r-159v; 1550, ff. 156r-156v), ambos textos proceden de la misma fuente -al menos, no ofrecen microvariantes notables-, pero los añadidos de 1550 parecen más correcciones. El hecho de que no se desarrollen nuevos núcleos narrativos nos obliga más a pensar en aclaraciones que en verdaderos añadidos. En el primer caso, quien corrige percibe cierta oscuridad en "viene vn monumento armado / y dentro del monumento / viene vn cuerpo sepultado", por lo que decide agregar un par de octosílabos que aclaren el sentido de la imagen: "vi en vn monumento armado / y dentro del monumento / viene un ataud de palo / y dentro del ataud / venia vn cuerpo finado" -el cambio de sepultado a finado permite comprobar que se trata de una intervención correctiva, dado que el cuerpo no puede en efecto estar sepultado-; en el segundo caso, se trata de otra amplificación en la que el registro más tradicional que conmina a no quejarse ("calledes hija calledes / calledes vrraca hernando") se convierte en 1550 en una secuencia de pregunta y respuesta: "porque llorays mis donzellas / porque hazeys tan grande llanto / no lloreys assi señoras / que no es para llorallo"; en el tercer caso, la amplificación es redundante y carece de ingenio ("...murio como cauallero / con sus armas peleando"):

POr aquel postigo viejo que nunca fuera cerrado vi venir pendon bermejo con trezientos de cauallo en medio delos trezientos viene vn monumento armado y dentro del monumento
POr aquel postigo viejo que nunca fuera cerrado vi venir pendon bermejo con trezientos de cauallo en medio delos trezientos vi en vn monumento armado y dentro del monumento viene un ataud de palo 
viene vn cuerpo sepultado Fernandarias ha por nombre fijo de Arias gonçalo llorauan le cien donzellas todas ciento hijas dalgo todas eran sus parientas en tercero y quarto grado las vnas le dizen primo otras le llaman hermano las otras dezian tio otras lo llaman cuñado sobre todas lo lloraua aquessa Vrraca hernando y quan bien que la consuela esse viejo Arias gonçalo calledes hija calledes calledes vrraca hernando

que si vn hijo me han muerto ay me quedauan quatro no murio por las tauernas ni alas tablas jugando mas murio sobre çamora vuestra honrra resguardando (1546, ff. 159r-159v). y dentro del ataud venia vn cuerpo finado Fernandarias ha por nombre fijo de Arias Gonçalo llorauan le cien donzellas todas ciento hijas dalgo todas eran sus parientas en tercero y quarto grado las vnas le dizen primo otras le llaman hermano las otras dezian tio otras lo llaman cuñado sobre todas lo lloraua aquessa Vrraca Hernando y quan bien que la consuela esse viejo Arias Gonçalo porque llorays mis donzellas porque hazeys tan grande llanto no lloreys assi señoras que no es para llorallo que si vn hijo me han muerto ay me quedauan quatro no murio por las tauernas ni alas tablas jugando mas murio sobre çamora vuestra honrra resguardando murio como cauallero con sus armas peleando

(1550, ff. 156r-156v).

Este procedimiento de amplificar en zonas concretas del romance se repite en "En sancta Gadea de Burgos" (1546, ff. 153v-155r) y "En sancta Agueda de Burgos" (1550, ff. 156v-158r), donde al cambio en el topónimo sigue un reacomodo en un par de octosílabos ("las juras eran tan fuertes / que al buen rey ponen espanto") y la amplificación de los símbolos de poder sobre los que jura ("y con vnos euangelios / y vn crucifixo en la mano”). Quizá lo más llamativo sea la ampliación de un par de octosílabos ("alli le toma la jura / el Cid al rey castellano"), reelaborados en 1550 como cuatro octosílabos para explicar la situación con mayor detalle: 
A)

En sancta Gadea de Burgos do juran los hijos dalgo alli le toma la jura

el Cid al rey castellano

B)

las juras eran tan fuertes

que al buen rey ponen espanto

C)

sobre vn cerrojo de hierro

y una ballesta de palo

(1546, ff. 153v-154r).
A)

En sancta Agueda de Burgos do juran los hijos dalgo le toman jura a Alfonso por la muerte de su hermano tomaua sela el buen Cid esse buen Cid Castellano

C) sobre vn cerrojo de hierro y una ballesta de palo y con vnos euangelios y vn crucifixo en la mano

B)

las palabras son tan fuertes que al buen rey ponen espanto (1550, ff. 156v-157r).

Entre los vv. 34-35 de la versión de 1546, se añade una digresión narrativa que sirve de refuerzo al conjunto, donde uno de sus caballeros le aconseja seguir con la jura ${ }^{11}$. Todos estos esfuerzos parecen apuntar en una misma dirección: ampliar la versión, por medio de remiendos sutiles que no llamen mucho la atención, para mejorar su construcción narrativa.

\section{¿VERSIONES?}

En "Cada dia que amenece" (1546, ff. 155r-155v) / "Dia era delos Reyes" (1550, ff. 162r-163r), pasamos de una versión de 34 vv. a otra de $78 \mathrm{vv}$., pero con un grupo tan importante de variantes que podríamos pensar en dos versiones distintas. Aunque muchas de las ampliaciones están bien identificadas y siguen el patrón anterior de sumar conjuntos de versos en distintas zonas -diez versos al principio de la de 1546, otros diez más entre los vv. 8-9 de la versión primitiva, 2 vv. entre 10-11, 2 vv. entre 11-12, 2 vv. entre 14-15, 18 vv. entre 16-17-, hay un grupo

11 "Las juras eran tan fuertes / que el rey no las ha otorgado / alli hablo vn cauallero / que del rey es mas priuado / hazed la jura buen rey / no tengays desso cuydado / que nunca fue rey traydor / ni papa descomulgado" $(1550$, f. $157 \mathrm{v})$. 
de versos al principio del romance que parece apuntar más bien al concepto de versión:

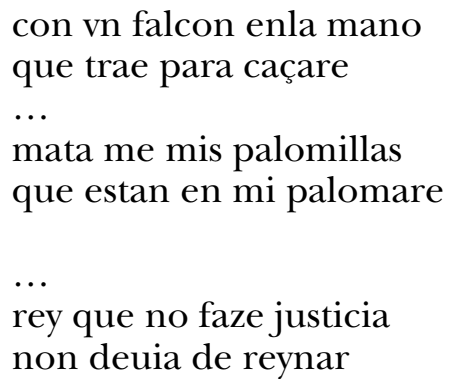

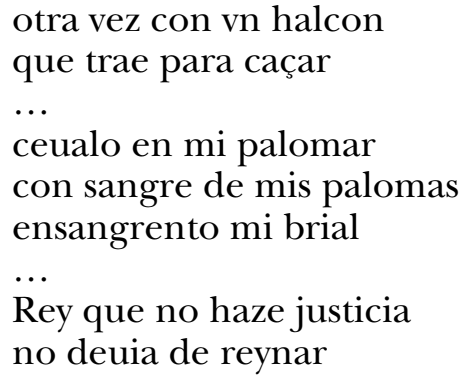

(1550, ff. 162r-162v).

Al final, sin embargo, sorprende que las que parecían versiones distintas vuelvan a coincidir en sus mínimos detalles -con excepción de alguna errata, como que ad vos/ quedauos o la mayúscula inicial de Maria-, lo que nos permite volver al concepto de versión editorial:

mandar le quiero vna carta mandar le quiero llamare las palabras no son dichas la carta camino vae mansajero que la lleua dado la auia a su padre malas mañas aueys conde no vos las puedo quitare que cartas que el rey vos manda no me las quereys mostrare no era nada my hijo sino que vades allae que ad vos aqui hijo yo yre en vuestro lugare nunca dios a tal quisiesse ni santa maria lo mande sino que adonde vos fueredes que vaya yo adelante

(1546, ff. 155r-155v). mandar le quiero vna carta mandar le quiero llamare las palabras no son dichas la carta camino vae mansajero que la lleua dado la auia a su padre malas mañas aueys conde no vos las puedo quitare que cartas que el rey vos manda no me las quereys mostrare no era nada my hijo sino que vades allae quedauos aqui hijo yo yre en vuestro lugare nunca dios a tal quisiesse ni santa Maria lo mande sino que adonde vos fueredes que vaya yo adelante

(1550, f. 163r).

En otra ocasión excepcional, el añadido circulaba en la tradición. Me refiero a "O Belerma, O Belerma..." (1546, ff. $254 v-255 v ; 1550$, ff. 269v-270v), al que se le agrega a manera 
de coda "Muerto yace Durandarte" (como ya había advertido Rodríguez-Moñino en 1967, p. 26). El romance de Durandarte fue bien conocido por los glosadores, quienes lo glosaron y recortaron en distintas oportunidades con extensión muy diferente; Giuliana Piacentini documenta al menos cinco estados redaccionales distintos del romance, con $42 \mathrm{vv}$., $24 \mathrm{wv}$., $11 \mathrm{vv}$., $16 \mathrm{vv}$. (empezando por la segunda estrofa) y $16 \mathrm{vv}$. (empezando por el principio; 1990, pp. 154-157). La versión del Cancionero de romances de 1546 coincide, esencialmente, con la versión más extensa del romance conservada en la glosa de Alberto Gómez (Rodríguez-Moñino 1997, núms. 222 y 223), lo que confirma el interés del impresor en recoger la versión más amplia y, consecuentemente, más completa desde una perspectiva narrativa. De hecho, la de Nucio de 1550 sería la más extensa de las conservadas: luego del cruce con "Muerto yace Durandarte" suma 64 wv. No es extraño que a Nucio le haya llamado la atención desde el principio el romance de la glosa de Alberto Gómez, no sólo por su amplitud, sino por los detalles narrativos que se perfilaban gracias a la glosa y que no pocas veces recuerdan episodios de la Chanson de Roland (Piacentini 1990, pp. 157-160). En la edición de 1550, como una continuación natural de la agonía de Durandarte y de la petición que hace a Montesinos de llevar su corazón a Belerma, se agrega la muerte, inhumación y extirpación del corazón al hilo de un romance que probablemente circulaba ya de forma independiente ("Muerto yace Durandarte"), aunque la versión de Nucio no coincide estrictamente con las otras conservadas en pliegos (Rodríguez-Moñino 1997, núms. 659 y 660), por lo que bien pudo ser escrita o reescrita para esta versión.

En "La triste reyna de Napoles" (1546, ff. 262v-263r) y "Emperatrizes y reinas" (1550, ff. 277v-278v), se pasa de una versión corta de $26 \mathrm{vv}$. a otra extensa de 54 vv., pero con tal cantidad de versos reformulados que no pueden sino considerarse como versiones distintas. Como apunta Vicenç Beltran, de la versión de 1546 "no hay casi versos reproducidos literalmente" y "el conjunto da la impresión de un arreglo para cantar, reducido en su extensión y maltratando el texto, según se acusaba con frecuencia a los músicos" (2017, p. 64). La versión que aparece en la Silva de varios romances de 1550 sería, por el contrario, producto de un "refundidor" que "introduce nuevos personajes" como "resultado de la estancia de Fernando el Católico en Nápoles, entre el verano de 1506 y 1507 " o "algo posterior a su vuelta" y 
dota de coherencia al conjunto (Beltran 2017, pp. 62-63). La minuciosa identificación de los personajes nobiliarios sugiere un romance remodelado en un ambiente cortesano, solidario con otros tres de la Silva de varios romances vinculados al reino de Aragón ("En el tiempo en que reinaba", "Don Ramiro de Aragón" y "Miraba de Campoviejo"). Aquí, el de 1550 de Nucio parece un arreglo para celebrar el paso de Fernando, el Católico, por Nápoles, mientras que la versión primitiva de Nucio y la arreglada de Esteban de Nájera pudieron "haber sido extractadas de glosas" (p. 65). "En el tiempo en que reinaba" y "Don Ramiro de Aragón", señala Beltran, "se asocian al tipo de romances eruditos que en aquel momento publicaban Fuentes o Sepúlveda" (id.). En resumen, nos encontramos ante dos versiones de un romance genealógico cuyos temas parecen interesar poco fuera del contexto de las cortes, compuesto probablemente como parte de "la campaña publicitaria de Fernando el Católico con ocasión de la conquista de Nápoles" (p. 56). Resulta difícil precisar la procedencia de las versiones, entre las capillas musicales, versiones recortadas para glosar o amplificadas por refundidores para contribuir a una causa política; sea cual sea el origen de las versiones, queda claro que entre los impresores, Nucio en Amberes o De Nájera en Zaragoza, la mejor versión es siempre la de mayor extensión y por ello la más completa.

Nucio no desconoce que el romance es "poesía que vive en variantes", pero su concepto de variante no parece ser el de la tradición folclórica. De "Esperança me despide" (1546, ff. 250r-250v; 1550, ff. [264r]-264v y 264v), colocó dos versiones distintas, una detrás de la otra, en su edición de 1550 . Conservó el mismo texto de 1546, apenas con una microvariante (damor/ d'amor), para sumar inmediatamente otra versión de menor extensión en un estilo más llano donde se evita la repetitio y se reduce el listado de paradojas. Mientras que la versión compartida en 1546 y 1550 consolida el textus receptus que circuló en la imprenta desde 1511 en el Cancionero general (2004, núm. 436), la nueva versión de 1550 sugiere la superación de una estética cancioneril -práctica que se solidariza con la poda de las glosas a los romances. Esta doble versión no debió llamar la atención de Nucio, pues alrededor había colocado varias contrahechuras de tendencia moral y estilo culto ${ }^{12} \mathrm{e}$, incluso, como

12 Como ya se presumía desde sus mismos títulos: "Romance de Diego de san pedro contrahaziendo el viejo que dize yo me estaya en baruadillo", 
sucede con "Esperança me despide", en varios casos recoge el romance modelo y su contrahechura ${ }^{13}$. Como sucedió con las contrahechuras, el entusiasmo del compilador le sugiere mantener juntas estas versiones para comparar más fácilmente el estilo repetitivo y conceptuoso de las modas cancioneriles con la expresión más llana y directa que conducirá al romancero historiado.

En el caso de todas estas versiones impresas, donde se fluctúa entre la innovación y la conservación, no puede evitarse pensar en el influjo de la oralidad; como ha escrito Virginie Dumanoir a propósito de otro caso:

los textos manuscritos e impresos dejan transpirar una vida oral innegable, cuyas huellas son notables en descuidos inexplicables sin el paso por fallos de la memoria, de la pluma o del corrector. Y los llamados errores no se tienen que borrar, porque son las puertas abiertas a la dimensión oral de los romances, sin la cual no llegan a considerarse en la integralidad de su ser. La versión del puño y letra de Francisco Morán de la Estrella resulta ser, desde este punto de vista, una auténtica joya. Múltiples despistes en el cómputo silábico lo llevan a romper la regularidad métrica; solo se entiende si imaginamos una copia a partir de una mala memorización o al hilo de una interpretación. De haber copiado el texto a partir de un manuscrito o impreso anterior, habría sabido

1546, ff. 231r-231v; "Otro del mesmo trocado por el que dize reniego de ti mahoma", 1546, f. 231v; "Romance mudado por Diego de çamora por otro q dize: ya desmayan los franceses", 1546, f. 238r; "Otro romance hecho por cumillas contrahaziendo al de digas me tu el hermitaño", 1546, f. 248r; "Otro romance contrahecho", 1546, ff. 268r-269r.

13 Ya desde la primera edición de 1546: "Otro romance contrahaciendo este del conde" (1546, ff. 91r-91v) repite con algunas ampliaciones las palabras del paje en un romance previo, "Media noche era por filo / los gallos querian cantar" (1546, f. 87v, vv. 283-295); al "Romance que dizen por la matança va el viejo" siguió "Otro romance contrahaziendo el de arriba mudado en otro proposito y fundado sobre la yda de vn cauallero a curarse con el palo delas Indias" (1546, ff. 188r-189v); al "Romance del rey Ramiro" se le agregó su contrafactum, "Otro romance contrafaziendo el de arriba" (1546, ff. 232r-232v), y "Sin dicha vi vna morada" (titulado "Otro romance contra hecho", 1546, ff. 268r-269r) es una contrahechura amorosa y muy amplificada de "Miraua de campo viejo" (1546, f. 260r). En 1550, se repitieron estos contrafacta (1550, ff. 198r-200r, 245v-247r, 252r-252v, 262r-262v, 283r-284r) y se sumaron algunos, como "Esperança me despide" y "En Burgos esta el buen rey" (1550, ff. 295v-298v); el último, reescritura con un centenar de octosílabos más de "En essa ciudad de burgos" (1546, ff. 177v-179r, y 1550, ff. 185v-186v). Véase Higashi, en prensa. 
dónde terminaban los renglones. Dibuja, con tantas vacilaciones, el perfil de un texto que hace frontera entre la oralidad y la escritura (2012, pp. 519-520).

A contrapelo de esta frontera -o quizá más que nunca en el sentido de ella-, las versiones con más variantes de Nucio parecen continuar la tendencia del zurcido editorial, ahí donde se expresan tácitamente los derechos que el impresor podía atribuirse durante el proceso para crear una versión "añadida" que superara en extensión y detalles a todas las conocidas. Entre la oralidad y la escritura, la imprenta no pudo quedar al margen de los cambios con la intención de ofrecer un texto novedoso a su público lector.

\section{VERSIONES DE IMPRENTA}

Las tendencias analizadas hasta aquí permiten ver una intención unitaria de ampliación de los textos, con el consecuente mejoramiento narrativo, atribuible en un buen número de casos al mismo impresor que las encargaría a algún poeta de su círculo. Estas prácticas de variación, que solemos identificar con la oralidad, no fueron privativas del repentismo de la calle o la plaza pública y pasaron, con aparente fluidez, a las cortes y a las imprentas. El que, como hoy, la oralidad domine la comunicación entre las personas, fue un factor que condicionó su situación privilegiada como modelo para otros campos. Si atendemos nada más a la reescritura de los principios de los romances, rápidamente comprobaremos que no era ajena a las modas cortesanas en cancioneros manuscritos y cartapacios poéticos. Como ha señalado Virginie Dumanoir en un artículo de 1998:

Es interesante notar que lo que encontramos aquí como regla de la reescritura culta de los romances tiene también vigencia dentro del conjunto de las variantes registradas en la tradición romanceril oral. Diego Catalán subraya así, tras el estudio de las versiones compiladas por los miembros del Seminario Menéndez Pidal, que el principio y el final del romance son las partes que dan lugar a las variaciones más numerosas ("Los modos de producción y «reproducción» del texto literario y la noción de apertura", en Homenaje a Julio Caro Baroja, Madrid, Centro de Investigaciones 
Sociológicas, 1978, p. 263). Salvo en dos de los casos que aquí estudiamos, la reescritura culta utiliza preferentemente la primera parte de un romance, tal vez porque es la que más recuerdo suele dejar en la mente de su público, que así puede apreciar con mayor facilidad la reescritura (p. 55, n. 44).

En el caso de estos romances "añadidos" por Nucio para su edición de 1550, podemos apreciar huellas de procedimientos tradicionales, sin duda, aunque todo parece apuntar a una intención editorial programática unitaria que se expresó desde su misma portada, en que los romances se presumen "añadidos".

A menudo, estas reescrituras han sido vistas como versiones recortadas por malos glosadores que, ante la necesidad de escribir una glosa, reducían el romance primitivo a su mínima expresión. Ya Menéndez Pidal afirmaba que "fueron los glosadores los que contribuyeron a propagar versiones acortadas y truncas" de Gerineldos (1953, p. 73). Menéndez Pidal atribuía estos recortes a los gustos generalizados de la época por versiones erosionadas durante las sesiones en las que los textos eran interpretados por las capillas musicales regias:

La predilección por el final brusco la vemos dominar ya entre los músicos y romancistas de la corte de los Reyes Católicos, cuando en 1489 se escribe y se armoniza en la capilla real el Sobre Baza estaba el rey, referente a la guerra de Granada, o cuando en 1495 se lanza a la popularidad oral el otro romance La triste reina de Nápoles, para favorecer la expedición del Gran Capitán a Sicilia; ambos romances se compusieron truncados en modo repentino e indeciso $(i d$.$) .$

Avanzado el siglo xvi, y a la luz del análisis de estas versiones imperfectas de Nucio que se completan en 1550, podemos afirmar que, al menos para algunos impresores, no se trató de recortar octosílabos, sino de ampliar los romances para prolongar el placer de la lectura con la suma de nuevos núcleos narrativos, al principio, medio y fin, incluso sin importar que con una nueva presentación se perdiera la posibilidad de identificar al romance por su incipit.

En el caso de Nucio, se ha enfatizado siempre su modernidad al recoger romances de la tradición y reunirlos bajo una forma unitaria (la del romancero), pero quizá deba llamarse más la atención sobre su afán de esquilmarlos de las glosas cuando 
lo normal era eliminar el romance por la obviedad de tenerlo al cierre de cada estrofa (Fuente Fernández 1990, p. 168). Si estos romances se glosaron fue porque ofrecían cierta resistencia u opacidad semántica que invitaba a reescribirlos acompañados de su glosa. La crítica a menudo ha resaltado la brevedad del romancero viejo, pero ciertamente solía recurrirse a versiones breves y algo oscuras para poder glosarlas mejor; para Rengifo, en 1592, era indispensable que el texto glosado fuera un juego de palabras o tuviera rimas que facilitaran la glosa (Fuente Fernández 1990, p. 160). Algo semejante sucedía con los motes glosados; como ha apuntado ya Isabella Tomassetti, "se trata, en la mayoría de los casos, de un texto axiomático y críptico, apto para constituir una suerte de emblemática sentencia y, por consiguiente, especialmente indicado para ser objeto de exégesis" (2017, p. 168); resulta difícil no ver algunas de estas características en los primeros romances glosados durante la consolidación del género en la corte de los reyes católicos (Tomassetti 2017, pp. 212-217). Nuestra idea de que las versiones del romancero viejo que más gustaban eran breves y tenían un estilo conciso y elusivo debe confrontarse con los hechos: fueron los que primero y mejor se recogieron porque estas formas concisas eran requisitos indispensables para ser objetos del interés de los glosadores. De ahí el éxito de romances como Fonte frida, Rosa fresca, Durandarte, Durandarte, etc., cortos y llenos de sugerencias que los glosadores explotarían.

Si muchos de los textos del romancero viejo están caracterizados por su brevedad, sus comienzos in medias res, su fragmentismo, sus finales truncos y otros rasgos afines, es en parte debido a los requisitos impuestos por la glosa. Como ha señalado Paloma Díaz-Mas, "esta insistencia en el carácter fragmentario nos hace olvidar a veces otra verdad que no se le escapó al propio Menéndez Pidal: que, al mismo tiempo que un gusto por los textos fragmentarios o truncos, existe en la época un notable gusto por la amplificatio sobre la base de temas romancísticos" (2000, p. 67). Los mejores romances para glosar debieron ser los más truncos y fragmentarios porque en esas zonas de indeterminación estaba la oportunidad para amplificar los textos y aclarar sus contenidos. Al esquilmar Nucio los romances de sus glosas en 1546, obtuvo en muchos casos un efecto no deseado -lo que calificó de imperfección- que pudo revertir con las nuevas versiones añadidas de 1550. El gusto por los romances más extensos explica que su selección comience con un romance del 
conde Dirlos de 1366 vv. y que casi una mitad de los añadidos sean romances breves que en su versión de 1546 cuentan entre 14 y 26 vv. -aunque algunos, claro, rebasan la cincuentena.

Este gusto por el detalle y el incremento de la materia narrativa debe vincularse, por supuesto, al repunte de otro hito en el romancero impreso, como parte de un mismo impulso solidario: el romancero historiado que pondrían de moda Lorenzo de Sepúlveda y Alonso de Fuentes por esos mismo años y que, si en el imaginario crítico de los sabios del siglo xix pareció esquemático y falto de inspiración, al grado de definirlo negativamente como romancero erudito (Higashi 2018, pp. 47-74), fue una de las estrategias de mercado que mejores resultados dio en el siglo XVI para terminar de posicionar el romancero entre los gustos de un público urbano. Si el romancero entró por sus adaptaciones cortesanas a través de la glosa, el juego y los repertorios de las capillas musicales, para después popularizarse gracias al pliego suelto entre una clase urbana que aspiraba a participar de estas modas, aunque fuera desde la distancia del pliego (trayecto magníficamente trazado en Beltran 2016), su consolidación definitiva deberá esperar al quinquenio de 1546-1551 para que entre los impresores empiece a proliferar un romancero de autor con romances originales compuestos expresamente sobre fuentes autorizadas, tras el magisterio de la historia como paradigma de una literatura ejemplar y donde la complejidad anecdótica, la digresión y el detalle serían los primores de una hechura a medida.

\section{REFERENCIAS}

Asensio Jiménez, Nicolás 2016. “¿Puede haber ecdótica en el romancero tradicional?”, Abenámar, Cuadernos de la Fundación Ramón Menéndez Pidal, 1, pp. 11-16.

Beltran, Vicenç 2016. El romancero: de la oralidad al canon, Reichenberger, Kassel.

Beltran, Vicenç 2017. Segunda parte de la Silva de varios romances... 1550. Coordinación general de José J. Labrador Herraiz, Frente de Afirmación Hispanista, Madrid.

Bénichou, PAul 1968. Creación poética en el Romancero tradicional, Gredos, Madrid.

Cancionero de romances 1546. Cancionero de Romances en que estan recopilados la mayor parte delos romances castellanos que fasta agora sean compuesto, En casa de Martin Nucio, En Enveres. [Ejemplar de la Bibliothèque Nationale de France, Bibliothèque de l'Arsenal, RESERVE 8- BL- 16099.] 
Cancionero de romances 1550. Cancionero de Romances en que estan recopilados la mayor parte delos romances castellanos que fasta agora se an compuesto, Nuevamente corregido, emendado, y añadido en muchas partes, En casa de Martin Nucio, En Envers. [Ejemplar de la Bayerische Staatsbibliothek, Munich. Rar. 925.]

Castillo, Hernando del 2004 [1511]. Cancionero general. Ed. Joaquín González Cuenca, Castalia, Madrid, 5 ts.

Catalán, Diego 1959. "El motivo y la variación en la trasmisión tradicional del romancero", Bulletin Hispanique, 61, 1/2, pp. 149-182.

Catalán, Diego 1982. "Hacia una poética del romancero oral moderno", en Actas del Cuarto Congreso Internacional de Hispanistas celebrado en Salamanca, agosto de 1971. Dir. Eugenio de Bustos Tovar, Asociación Internacional de Hispanistas-Consejo General de Castilla y León-Universidad de Salamanca, Salamanca, t. 1, pp. 283-295.

Cid, Jesús Antonio 1995. "El romancero oral hispánico. Una poética de la variación”, en Culturas en la Edad de Oro. Dir. José María Díez Borque, Editorial Complutense, Madrid, pp. 45-81.

Dèbax, Michélle 1990. "En torno a la edición de romances", en La edición de textos: actas del I Congreso Internacional de Hispanistas del Siglo de Oro. Eds. Pablo Jauralde, Dolores Noguera y Alfonso Rey, Tamesis Books, London, pp. 43-59.

Díaz-Mas, Paloma 2000. "Cómo se releyeron los romances: glosas y contrahechuras de Tiempo es, el caballero, en fuentes impresas del siglo Xvi", en Historia, reescritura y pervivencia del romancero, estudios en memoria de Amelia García-Valdecasas. Ed. Rafael Beltrán, Publicacions de la Universitat de València, València, pp. 67-90.

Díaz-Mas, Paloma 2013. "Lecturas y reescrituras de romances en los siglos de oro: glosas, deshechas y otros paratextos", Edad de Oro, 32, pp. 155-175, doi: 10.15366/edadoro2013.32; hdl: http://hdl.handle. net/10261/108326.

Díaz-Mas, Paloma 2017. "Introducción", en Cancionero de romances, edición facsímil. Prólogo de José J. Labrador, introducción de Paloma Díaz-Mas, coordinación de la edición de José J. Labrador Herraiz, Frente de Afirmación Hispanista, Madrid, pp. 13-56.

Di Stefano, Giuseppe 1968. "Marginalia sul romanzero", en Miscellanea di studi ispanici, Instituto di Lingua e Letteratura Spagnola dell’Università di Pisa, Pisa, pp. 139-178.

Di Stefano, Giuseppe (ed.) 2010. Romancero, Castalia, Madrid.

Dumanoir, Virginie 1998. "De lo épico a lo lírico: los romances mudados, contrahechos, trocados y las prácticas de reescritura en el Romancero viejo”, Criticón, 74, pp. 45-64.

Dumanoir, Virginie 2003. Le Romancero courtois. Jeux et enjeux poétiques des vieux romances castillans (1421-1547), Presses Universitaires de Rennes, Rennes.

Dumanoir, Virginie 2012. "El problemático estudio de los romances viejos castellanos: «Durandarte, Durandarte»", en Literatura medieval y renacentista en España: líneas y pautas. Eds. Natalia Fernández Rodríguez y María Fernández Ferreiro, Universidad de Salamanca-Sociedad de Estudios Medievales y Renacentistas, Salamanca, pp. 517-526. 
DumanoIr, Virginie 2014. "De un impreso a otro: variatio y errata romanceriles", en La poesía en la imprenta antigua. Ed. Josep Lluís Martos, Universitat d'Alacant, Alacant, pp. 267-290.

Fuente Fernández, Francisco Javier 1990. "Pliegos sueltos góticos de Praga: las glosas de romances”, Estudios Humanisticos. Filología, 12, pp. 157174.

García Esteban, Ana Pilar 2016. "El romancero fronterizo: versiones de El alcalde de Alhama en la tradición oral moderna”, Cuadernos de Aleph, 8, pp. 34-55.

Garvin, Mario 2007. Scripta manent. Hacia una edición crítica del romancero impreso (siglo XVI), Iberoamericana-Vervuert, Madrid-Frankfurt/M.

Garvin, Mario 2014. "La lógica del pliego suelto. Algunos apuntes sobre la materialidad en la transmisión poética”, en La poesía en la imprenta antigua. Ed. Josep Lluís Martos, Universitat d'Alacant, Alacant, pp. 295-309.

Garvin, Mario 2017. "Mecanismos del cambio textual en el romancero impreso", en Variación y testimonio único: la reescritura de la poesía. Ed. Josep Lluís Martos, Universitat d'Alacant, Alacant, pp. 129-140.

GonzÁlez, Aurelio 2001. "El tesoro del Romancero: la variación. Dos ejemplos de la tradición americana”, Anales de Literatura Hispanoamericana, 54, 30, pp. 53-67.

González, Aurelio 2012. "El motivo: unidad narrativa en los romances caballerescos”, Revista de Poética Medieval, 26, pp. 129-147.

González Ramírez, David 2011. Del taller de imprenta al texto crítico. Recepción y edición de la "Guía y aviso de forasteros" de Liñán y Verdugo, Universidad de Málaga, Málaga.

Higashi, Alejandro 2012. "El perfil de la variante en el romancero épico", en Estudios de literatura medieval. 25 años de la Asociación Hispánica de Literatura Medieval. Eds. Antonia Martínez Pérez y Ana Luisa Baquero Escudero, Universidad de Murcia, Murcia, pp. 517-526.

Higashi, Alejandro 2014. "Función de la microvariante: del pliego suelto al Cancionero de romances", en La poesía en la imprenta antigua. Ed. Josep Lluís Martos, Universitat d'Alacant, Alacant, 305-324.

Higashi, Alejandro 2015. "El Cancionero de romances como paradigma editorial para el romancero impreso del xvi: análisis de microvariantes", Boletín de la Real Academia Española, 95, pp. 85-117.

Higashi, Alejandro en prensa. "Versiones en el Cancionero de romances", en Actas del Coloquio Internacional de la Asociación Hispánica de Literatura Medieval "Libros, lecturas y reescrituras", celebrado en Zaragoza en octubre de 2018.

López GUiL, Itzíar 2006. "Romancero y tradición oral: hacia una nueva interpretación del Romance del conde Arnaldos", en Blätter im Wind, Homenaje a Maya Schärer-Nussberg, Reichenberger, Kassel, pp. 69-84.

Martos, Joser Lluís 2017. "La fecha del Cancionero de romances sin año", Edad de Oro, 36, pp. 137-157, doi: 10.15366/edadoro2017.36.009.

Menéndez Pidal, Ramón 1953. Romancero hispánico (hispano-portugués, americano y sefardí). Teoría e historia, t. 1, Espasa-Calpe, Madrid.

Moreno, Charo 2009. "Los márgenes del romancero: versiones minoritarias, fragmentarias y anómalas", Pandora, 9, pp. 253-271. 
Nascimento, Braulio do 2001. "Invariantes, paráfrasis y variantes en la literatura oral”, Anales de Literatura Hispanoamericana, 30, pp. 37-51.

Pérez Priego, Miguel Ángel 2004. "El romance de «El prisionero»", en Estudios sobre la poesía del siglo XV, Universidad Nacional de Educación a Distancia, Madrid, pp. 265-280.

Piacentini, Giuliana 1990. "Una lectura de las glosas del Romance de Belerma", en Actas del Congreso Romancero-Cancionero. Ed. Enrique Rodríguez Cepeda y colaboración y bibliografía crítica de Samuel G. Armistead, José Porrúa Turanzas, Madrid, t. 1, pp. 153-164.

Piacentini, Giuliana y Blanca Periñán (eds.) 2002. Glosas de romances viejos. Siglo XVI, Edizioni ETS, Pisa.

Quarenta cantos 1550. Quarenta Cātos de diuersas y peregrinas historias, declarados y moralizados por el magnifico cauallero Alonso de Fuentes, en casa de Dominico de Robertis, difuncto, Seuilla. [Ejemplar de la Bibliothèque Nationale de France, Tolbiac, Rez-de-jardin-magasin, RES-YG-78.]

Rodríguez López-VÁzQuez, Alfredo 2000. "Introducción”, en Andrés de Claramonte, Dineros son calidad, atribuido a Lope de Vega. Edición crítica con estudio y notas de Alfredo Rodríguez López-Vázquez, Reichenberber, Kassel, pp. 1-108.

Rodríguez-MoÑino, Antonio 1967. "Introducción", en Cancionero de romances (Anvers, 1550). Edición, estudio, bibliografía e índices de Antonio Rodríguez-Moñino, Castalia, Madrid, pp. 7-106.

Rodríguez-MoÑino, Antonio 1997. Nuevo diccionario bibliográfico de pliegos sueltos poéticos, siglo XVI. Edición corregida y aumentada por Arthur L.-F. Askins y Víctor Infantes, Castalia, Madrid.

SÁnchez Romeralo, Antonio 1990. "La edición del texto oral", en La edición de textos: actas del I Congreso Internacional de Hispanistas del Siglo de Oro. Eds. Pablo Jauralde, Dolores Noguera y Alfonso Rey, Tamesis Books, London, pp. 69-77.

Tato, Cleofé 1999. "El romance «Miraba de Campoviejo»", Dicenda, Cuadernos de Filología Hispánica, 17, pp. 251-281.

Tomassetti, Isabella 2017. Cantaré según veredes. Intertextualidad y construcción poética en el siglo XV. Iberoamericana-Vervuert, Madrid-Frankfurt/M.

Valenciano, Ana 2016. "Reflexiones en torno a la edición del Romancero Tradicional de las Lenguas Hispánicas: pasado y presente”, Abenámar, 1, pp. 319-328. 